Published in "Journal of Natural Fibers doi: 10.1080/15440478.2020.1764454, 2020" which should be cited to refer to this work.

\title{
Isolation of Cellulose Nanofibers from Oryza sativa Residues via TEMPO Mediated Oxidation
}

\author{
Edwin S. Madivoli $\mathbb{D}^{\mathrm{a}, \mathrm{b}}$, Patrick G. Kareru $\mathbb{D}^{\mathrm{a}}$, Anthony N. Gachanja $\mathbb{D}^{\mathrm{a}}$, Samuel M. Mugo $\mathbb{D}^{\mathrm{c}}$, \\ David M. Sujeed, and Katharina M. Fromm (D) ${ }^{\mathrm{b}}$ \\ ${ }^{a}$ Chemistry Department, Jomo Kenyatta University of Agriculture and Technology, Nairobi, Kenya; ${ }^{b}$ Department of \\ Chemistry, University of Fribourg, Fribourg, Switzerland; 'Chemistry Department, McEwan University, Edmonton, \\ Alberta, Canada; dDepartment of Physical Sciences, Karatina University, Karuri, Kenya
}

\begin{abstract}
Cellulose nanocrystals (CNCs) or cellulose nanofibers (CNFs) with different morphologies, chemical, mechanical and physical properties can be obtained when microcrystalline cellulose is subjected to enzymatic, chemical or mechanical treatment. With the aim of utilizing cellulose nanofibrils (CNFs) from Oryza sativa, we isolated microcrystalline cellulose using the Kraft process, followed by successive fiber fibrillation using mechanical grinding, then (2,2,6,6-Tetrame thylpiperidin-1-yl)oxyl (TEMPO) mediated oxidation. Analysis of pulp fibers obtained after each treatment step revealed that fiber properties such as length, crystallinity and crystal size changed when the pulp was subjected to mechanical grinding, ultrasonication and TEMPO mediated oxidation. The degree of crystallinity of the fibers increased while crystal size and fiber length decreased after each treatment. TEMPO mediated oxidation led to a decrease in fiber length and an increase in degree of crystallinity of the fibers as compared to mechanical treatment and ultrasonication. It further introduced carboxyl functional groups $(\mathrm{COOH})$ on the surface of the fibrils, which implies that the nanofibers obtained in this study could be further functionalized. Hence, TEMPO mediated oxidation offers the possibility of further chemical functionalization of cellulose nanofibers isolated from agricultural residues.
\end{abstract}

\section{摘要}

微晶纤维素经酶、化学或机械处理后, 可以获得具有不同形貌、化学性 质、机械性质和物理性质的纤维素纳米晶体(CNCS)或纤维素纳米纤维 (CNFs). 为了利用来自水稻的纤维素纳米纤维(CNFs), 我们用牛皮纸法分 离微晶纤维素, 然后用机械研磨法连续纤维纤颤, 然后(2,2,6,6-四甲基哌 啶-1-基)氧化(TEMPO)介导氧化. 对每个处理步骤后得到的纸浆纤维进行分 析，发现当纸浆经过机械研磨、超声波处理和TEMPO介导氧化处理后， 纤维的长度、结晶度和晶体大小等特性发生了变化. 各处理后纤维结晶度 均有所提高, 晶粒尺寸和纤维长度均有所减小. 与机械处理和超声处理相 比, TEMPO介导的氧化导致纤维长度缩短, 纤维结晶度增加. 进一步在纤 维表面引入羧基官能团 $(\mathrm{COOH})$, 说明本研究得到的纳米纤维可以进一步 功能化. 因此, TEMPO介导氧化为进一步实现从农业残留物中分离的纤维 素纳米纤维的化学功能化提供了可能.

\section{KEYWORDS}

Cellulose; morphology; particle size distribution

\section{关键词}

纤维素; 形态、particle size distribution 粒度分布

\section{Introduction}

There is great interest in the development of green, bio-based and biodegradable materials from natural resources to meet the demand for materials for engineering purposes (Collazo-Bigliardi,

CONTACT Edwin S. Madivoli edwin.madivoli@jkuat.ac.ke $\mathbf{\theta}$ Chemistry Department, Jomo Kenyatta University of Agriculture and Technology, P.O Box 62,000-00200, Nairobi, Kenya 
Ortega-Toro, and Boix 2018). With a global production of 220 billion tonnes annually, agricultural residues have attracted attention as precursors for the production of environmentally sustainable materials (Islam et al. 2018; Jorfi and Foster 2015; Kar, Rana, and Pandey 2015). Residues such as rice husks (Barbash, Yaschenko, and Shniruk 2017; Begun et al. 2013), coffee husks (CollazoBigliardi, Ortega-Toro, and Boix 2018), wheat straw (Bian, et al. 2019a), sisal fibers (Bhimte and Tayade 2007), walnuts (Hemmati et al. 2018), corn cobs (Boufi and Chaker 2016), cladophora fibers (Camacho, Gerongay, and Macalinao 2013), lotus stalks (Chen et al. 2014), vine shoots (El Achaby et al. 2018), roselle (Kian et al. 2017), or agave (Ponce et al. 2013) are rich sources of cellulose nanofibers with potential applications in composite materials (Torres et al. 2013). In developing countries such as Kenya where the annual rice production stands at 45,000-50,000 tons per year, these residues are increasingly becoming a point of concern due to the high amount generated annually. These residues are usually buried in soil or burnt in the open, an approach which leads to environmental degradation through the introduction of harmful products into the atmosphere. As a result, there is a need to come up with effective and economical ways in which these agricultural residues can be utilized through chemical, biological, or thermal conversion to produce cellulose nanofibers (Bian, et al. 2019a).

Cellulose nanofibers (CNF) and cellulose nanocrystals (CNCs) are usually prepared using chemical, physical, biological or oxidation methods (Kar, Rana, and Pandey 2015; Szczęsna-Antczak, Kazimierczak, and Antczak 2012). Chemical methods typically involve the use of strong acids by which the amorphous domains of the fibers are destroyed, yielding cellulose nanocrystals (CNCs) in which surface hydroxyl groups are esterified to yield corresponding acid esters (Karimi and Taherzadeh 2016; Torres et al. 2013). Cellulose nanofibers (CNFs) are also prepared when cellulose is subjected to mechanical treatment such as high-speed grinding, high-intensity ultrasonic treatment and steam explosion to obtain fibers of nanometer dimensions (Boufi and Chaker 2016). Biological treatments of cellulosic materials are based on enzymes such as cellulase that are produced by fungi, bacteria, protozoans, plants and animals to cleave the $\beta-1,4$ linkages of the fiber structures into simpler ones (Zhang and Zhang 2013). Since such treatments are more timeconsuming, they are often coupled with mechanical/chemical methods to yield faster and better CNF. Biological treatment has the advantage of producing nanofibers that are considered biocompatible and can be used to produce biomedical and pharmaceutical products. Enzymatic processes, compared to chemical ones, are also widely considered as environmentally friendly and result in longer nano-fibers that are characterized by a greater number of connections between nanofibrils (Corgie, Smith, and Walker 2011; de Aguiar et al. 2020). These are desirable characteristics of CNF used in biomedical applications such as wound dressings and reinforcement materials in nanocomposites. (Szczęsna-Antczak, Kazimierczak, and Antczak 2012). Moreover, recent research progress has led to the use of eutectic solvent and organic solid acids to isolate cellulose nanofibrils but utilization of these solvents is hampered by cost (Yu et al. 2019; Bian, et al. 2019b). The utilization of 2,2,6,6-tetramethylpiperidine-1-oxyl (TEMPO) as a catalyst during oxidation with hypochlorite allows the introduction of a carboxylic group in the $\mathrm{C}_{6}$ position on the surface of the fibers. The exposure of TEMPO-oxidized fibers to mechanical treatment results in easier defibrillation due to the generation of negative charges that repel the microfibrils against each other inside the cell wall resulting in cellulose nanofibers with a diameter of 3-4 nm (Menon et al. 2017).

In this study, cellulose was isolated from Oryza sativa husks through alkaline hydrolysis, bleached with $\mathrm{H}_{2} \mathrm{O}_{2} / \mathrm{CH}_{3} \mathrm{COOH}(1: 1.5 \mathrm{v} / \mathrm{v})$ mixture followed by conversion to nanofibrils through successive mechanical high-speed grinding followed by TEMPO mediated oxidation. A Fourier-transforminfrared spectrometer (FTIR) was used to determine the functional groups present while the particle size distribution and morphological fiber analysis were determined using a particle analyzer and a MorFi optical fiber length analyzer. The degree of crystallinity was determined via wide-angle $\mathrm{X}$-ray diffraction while the thermal properties were evaluated using a differential scanning calorimeter (DSC) and Thermal gravimetric analysis. The surface morphology and size of the isolated 
fibers were determined using scanning electron microscopy (SEM) and Transmission electron microscopy (TEM) respectively.

\section{Materials and methods \\ TEMPO-mediated oxidation}

Microcrystalline cellulose from Oryza sativa husks was prepared according to a previously established method (Madivoli et al. 2016; Murigi et al. 2014; Ponce et al. 2013). TEMPO-oxidized fibers were synthesized by dispersing $2 \mathrm{~g}$ microcrystalline cellulose (CE) in $50 \mathrm{ml}$ deionized water containing TEMPO $(0.32 \mathrm{mmol})$ and sodium bromide $(5.0 \mathrm{mmol})$ followed by addition of $\mathrm{NaClO}$ solution $(0.05 \mathrm{mmol} / \mathrm{g} \mathrm{CE})$ to the reaction. The reaction was maintained at $\mathrm{pH} 10$ by dropwise addition of $\mathrm{NaOH}(0.5 \mathrm{M})$ and monitoring changes in $\mathrm{pH}$ using a $\mathrm{pH}$ meter. The reaction was considered complete when the $\mathrm{pH}$ of the solution remained constant at $\mathrm{pH} 10$ without further addition of $\mathrm{NaOH}(0.5 \mathrm{M})$ solution. The reaction was quenched by the addition of ethanol followed by washing to neutral $\mathrm{pH}$ and centrifuging several times to remove inorganic salts and TEMPO (Zhou et al. 2018). $\mathrm{HCl}(2 \mathrm{M}$ ) was added to the suspension of oxidized cellulose to adjust the $\mathrm{pH}$ to 2 and the mixture was stirred at room temperature to convert the $\mathrm{C}_{6} \mathrm{COONa}$ groups to $\mathrm{C}_{6} \mathrm{COOH}$ groups. The carboxyl content of the pulp fibers was determined by potentiometric titrations where the fibers $(0.1 \mathrm{~g})$ were dispersed in water $(20 \mathrm{ml})$ and titrated with $\mathrm{NaOH}(0.1 \mathrm{M})$ solution (Barbosa et al. 2013; Isogai 2018; Rohaizu and Wanrosli 2017; Zhou et al. 2018). The carboxyl content was calculated using the following formulae:

$$
C_{0}=\left(\frac{N x V x 100}{M}\right)
$$

Where $\mathrm{C}_{0}$ is the carboxyl content $(\mathrm{mmol} / \mathrm{g}), \mathrm{N}$ is the titrant concentration $(\mathrm{mM}), \mathrm{V}$ is the volume $(\mathrm{ml})$ at the equivalence point and $\mathrm{M}$ is the dried pulp in grams (Barbosa et al. 2013). TEMPOoxidized fibers were then dispersed in distilled water, sonicated and lyophilized (Boufi and Chaker 2016; Hassan and Hassan 2016; Isogai 2018; Jonoobi et al. 2010; Zhou et al. 2018).

\section{Characterization of cellulose nanofibers}

The presence of functional groups was determined with a Bruker Tensor II FT-IR spectrophotometer model (Bruker, Ettlingen, Germany) using pressed KBr pellets prepared under a pressure of $7.5 \times 1 \mathbf{1 0}^{5}$ kPa for 3 min (Madivoli et al. 2016; Murigi et al. 2014). The diameters and length of pulp fibers were determined using a Techpap Morfi Optical fiber analyzer (Techpap, France) after disintegration and dilution to obtain a $0.1 \mathrm{~g} / \mathrm{l}$ solution (Chen et al. 2014). Particle size distribution was determined using a Malvern G3 S system (Malvern Instruments, Worcestershire UK) where $5 \mathrm{~mm}^{3}$ samples were loaded into a holder sealed with aluminum foil. The holder was placed in a dispersion unit and fibers were dispersed on a glass plate with a pneumatic pressure of $0.5 \mathrm{MPa}$, injection time of $10 \mathrm{~ms}$ and settling time of $60 \mathrm{~s}$ (Wang, Gardner, and Bousfield 2017). The XRD diffractogram was obtained using an STOE STADIP P X-ray Powder Diffraction System (STOE \& Cie GmbH, Darmstadt, Germany) equipped with a copper tube operating at $40 \mathrm{kV}$ and $40 \mathrm{~mA}$ irradiating the sample with a monochromatic $\mathrm{CuKa}$ radiation $(0.1542 \mathrm{~nm})$. The crystallinity index $\left(\mathrm{CI}_{\mathrm{XRD}}\right)$ and crystal size were calculated using the peak height method and Scherrer equation, respectively (Jonoobi et al. 2010; Madivoli et al. 2016). The hydrodynamic diameter was measured using a Bechman Coulter DelsaMax pro Dynamic light scattering analyzer (Indianapolis, United States). Differential Scanning Calorimetry (DSC) and Thermal Gravimetric Analysis (TGA) were carried out using a Mettler Toledo TGA/DSC 3+ (Mettler-Toledo $\mathrm{GmbH}$, Switzerland) by heating the samples

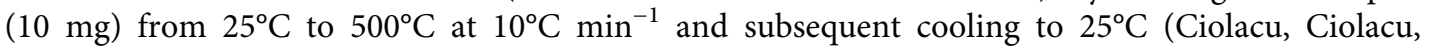
and Popa 2011; Ponce et al. 2013). The surface morphology of the fibers was evaluated using a Tescan Mira3 LM FE Scanning electron microscope operated at an accelerating voltage of $3 \mathrm{kV}$ 
(Kian et al. 2017). TEM micrographs were acquired on a Tecnai G2 Spirit (Thermo Fisher Scientific, Oregon USA) operated at $120 \mathrm{kV}$ after suspending the pulp fibers in ultrapure water $(18 \mathrm{M} \Omega . \mathrm{cm}$ Barnstead Genpure UV-TOC, Thermo Fisher scientific, Germany), and drop casting on carbon films 300 mesh (Electron microscopy science, CF300-CU).

\section{Results and discussions}

\section{TEMPO oxidation of cellulose}

Cellulose nanofibers could be obtained via the schematic representation in Figure 1.

Depending on the reaction conditions, the insoluble microcrystalline cellulose progressively disappears, and the solution becomes cloudy and well dispersed (Figure 1). The basic component for TEMPO-oxidized cellulose nanofibers are carboxylic acid functional groups introduced at the C-6 hydroxyl groups, which are sodiated at $\mathrm{pH} 10$. The sodium ion can be replaced through ion exchange to introduce other ionic species such as protons or other metal ions. The carboxylate may even bind to metallic nanoparticles such as silver, copper, iron or zinc, allowing to generate a composite with the oxidized fibers (Boufi and Chaker 2016; Isogai 2018; Zhou et al. 2018). In a first step, the CNF surface $\mathrm{C} 6$ carboxylate group was protonated with $\mathrm{HCl}$ to generate $\mathrm{CNF}$ containing carboxylic acid groups, as confirmed by functional group analysis. The carboxylic acid content is greatly influenced by the amount of oxidant used as at higher oxidant concentration there was a subsequent drop in the carboxylic content of the fibers as determined by potentiometric titration (Figure SF 1) (Isogai 2018). Potentiometric titration of TOCNF against NaOH (Figure SF 1) revealed that the carboxyl content of oxidized fibers was found to be $2.21 \pm 0.11 \mathrm{mmol} / \mathrm{g}$ of fibers as compared to native unoxidized cellulose that did not have carboxylic groups (Barbosa et al. 2013). Depending on the cellulose source and the reaction conditions involved during synthesis, the carboxyl content of TOCNF has been reported to be dependent on cellulose I crystal width which varies with the source of pulp fibers used (Isogai 2018).

\section{Characterization of CNF isolated from O. sativa husks}

For comparison purposes, the FT-IR spectra of O. sativa husk cellulose (RHCE), mechanical-treated cellulose (MTCE), ultra-sonicated cellulose (USCE) and TEMPO-oxidized cellulose (TOCNF) are depicted in Figure 2.

Signals between 3450 and $3350 \mathrm{~cm}^{-1}$ are due to the surface hydroxyl groups while the bands at $2902 \mathrm{~cm}^{-1}$ and $1328 \mathrm{~cm}^{-1}$ correspond to $\mathrm{CH}_{2}$ stretching vibrations. The absorption at $1213 \mathrm{~cm}^{-1}$ in the spectra was attributed to $\mathrm{C}-\mathrm{O}$ stretching while the absorption peaks at 1070 and $850 \mathrm{~cm}^{-1}$ refer to the C-O-C vibrational frequency and $\beta$-glycosidic linkage vibration, respectively (Johar, Ahmad, and Dufresne 2012). The bands from $465 \mathrm{~cm}^{-1}$ to $485 \mathrm{~cm}^{-1}$ belong to the bending vibration of Si-O while a peak at $1640 \mathrm{~cm}^{-1}$ corresponds to $-\mathrm{OH}$ bending vibrations as a result of cellulose water interactions (Begun et al. 2013; Jonoobi et al. 2010). As seen from the FTIR spectrum of cellulose, the low intensity of the absorbance peaks in the regions $1740-1745$ and $1235-1240 \mathrm{~cm}^{-1}$ indicates that the fibers have a low degree of acetylation as a result of the interaction of the fibers with acetic acid

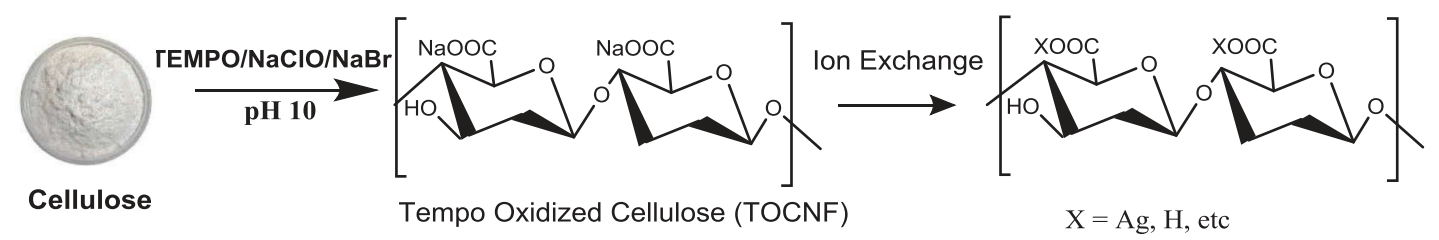

Figure 1. TEMPO-oxidized cellulose nanofibers (TOCNF) reaction scheme. 


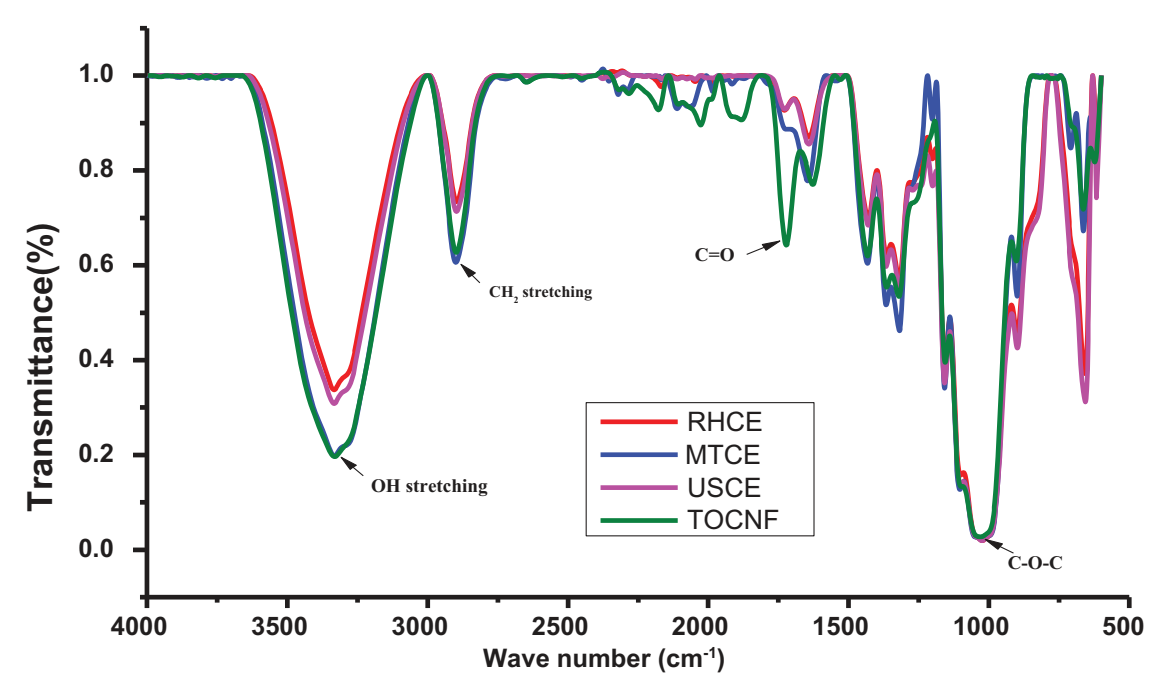

Figure 2. FT-IR spectra of $O$. sativa husk cellulose (RHCE), mechanical-treated cellulose (MTCE), ultra-sonicated cellulose (USCE) and TEMPO-oxidized cellulose (TOCNF).

during the bleaching cycle (Jonoobi et al. 2010). Normally, an intramolecular hydrogen bond in cellulose occurs at $3342 \mathrm{~cm}^{-1}$. Bands in the region between 3221 and $3280 \mathrm{~cm}^{-1}$ are assigned to the two crystalline cellulose allomorphs, cellulose $I_{\alpha}$ and cellulose $I_{\beta}$. A very small peak, normally shifted to lower wavenumbers, at $3147 \mathrm{~cm}^{-1}$, was attributed to hydrogen bonds occurring only in cellulose $\mathrm{I}_{\alpha}$. The band at $3147 \mathrm{~cm}^{-1}$ was assigned to the intramolecular hydrogen bonds present only in triclinic $\mathrm{I}_{\alpha}$ cellulose, whereas the band at $3319 \mathrm{~cm}^{-1}$ is proportional to the amount of monoclinic cellulose $I_{\beta}$ (Poletto, Ornaghi, and Zattera 2014). The main difference between native rice husk cellulose, mechanical-treated cellulose, ultrasonicated cellulose and TEMPO-oxidized cellulose is the signal at $1610 \mathrm{~cm}^{-1}$ for oxidized cellulose which corresponds to the $\mathrm{COO}^{-} \mathrm{Na}^{+}$group. The disappearance of this peak in acid-treated cellulose confirmed the conversion of $\mathrm{COO}^{-} \mathrm{Na}^{+}$to $\mathrm{COOH}$ with the $\mathrm{C}=\mathrm{O}$ peak appearing at around $1728 \mathrm{~cm}^{-1}$. (Okita et al. 2010)

\section{Morphological fiber analysis (MorFi)}

MorFi analysis was adopted to investigate the morphological characteristics of the O. sativa husks cellulose fibers and the results are depicted in Figure SF 2 and Table ST 1 (Chen et al. 2014). The data in Figure SF 4 and Table ST 1 show the average fiber characteristics of $O$. sativa husks cellulose. As a result of aggregation during the drying process, $42.7 \%$ of $O$. sativa husks fibers had fiber weighted mean lengths ranging between 23 and $45 \mu \mathrm{m}$ (Figure 4) as a result of aggregation during the drying process (Zimmermann et al. 2016). The average weighted length of hardwood pulp and softwood pulp has been reported to be 0.65 and $2.22 \mathrm{~mm}$, respectively (Chen et al. 2014). The circle equivalent diameter, high sensitivity circularity and the aspect ratio of cellulose are given in Table 1.

Circle equivalent (CE) diameter is the diameter of a circle with the same area as the $2 \mathrm{D}$ image of the particle while high sensitivity (HS) circularity values indicate whether the particles closely

Table 1. Quantitative characterization of particle size distribution of cellulose fibers.

\begin{tabular}{lcccc}
\hline & Mean & $\mathrm{D}[\mathrm{n}, 0.1]$ & $\mathrm{D}[\mathrm{n}, 0.5]$ & $\mathrm{D}[\mathrm{n}, 0.9]$ \\
\hline CE diameter & $8.6 \pm 7.5$ & 2.1 & 6.3 & 16.2 \\
HS circularity & $0.8 \pm 0.2$ & 0.5 & 0.9 & 0.9 \\
Aspect ratio & $0.7 \pm 0.2$ & 0.5 & 0.9 & 0.9 \\
\hline
\end{tabular}


resembled a circle and is the ratio of the object's projected area to the square of the perimeter of the object. A perfect circle has an HS circularity of 1 while an irregular object has an HS circularity value closer to 0 (Peng, Han, and Gardner 2012; Wang, Gardner, and Bousfield 2017). The CE diameters, HS and aspect ratio of cellulose were Gaussian distributed, but the mean diameters were in the micron scale dimensions with a vast majority being smaller than $10 \mu \mathrm{m}$. Because of irreversible agglomeration and aggregation in nonpolar matrices as a result of capillary forces, van der Waals forces and hydrogen bonding, the nanoscale dimension is usually lost during drying (Kar, Rana, and Pandey 2015; Peng, Han, and Gardner 2012; Zimmermann et al. 2016). Since particle size influences many properties of composite and is a valuable indicator of the quality and performance of these materials, the cellulose morphology is critical to modifying the rheological properties of resulting polymer composites (Wang, Gardner, and Bousfield 2017).

\section{Degree of crystallinity and crystal size}

The wide-angle diffractograms of cellulose fibers obtained from O. sativa husks are depicted in Figure 3.

The diffractograms obtained (Figure 3) were typical of semi-crystalline material since they are composed of a broad amorphous peak as well as crystalline peaks. It has been reported that the crystalline structure of cellulose is responsible for the peak observed at $22^{\circ}$ whereas hemicellulose and lignin, which are amorphous, are responsible for the peak observed at $16^{\circ}$ (Nascimento et al. 2016; Thygesen et al. 2005). These peaks at $2 \theta$ angles of $16^{\circ}, 22^{\circ}$ and $34^{\circ}$, respectively, attributed to the diffraction planes of (101), (002) and (040), are characteristic of type 1 cellulose while the degree of crystallinity was estimated to be $42 \%, 32 \%, 27 \%, 28 \%$ and $22 \%$ for, TOCNF, USCE, MTCE, ATRH and RHCE, respectively (Barbash, Yaschenko, and Shniruk 2017; Hooshmand et al. 2017). The crystallinity index of cellulose is affected by the treatment methods the fibers have been subjected to as highly crystalline cellulose is obtained when the pulp fibers are treated with strong acids such as $\mathrm{HCl}$ and $\mathrm{H}_{2} \mathrm{SO}_{4}$ while mechanical treatment such as balling yields fibers with less crystallinity. Moreover, the increase in fiber crystallinity after each treatment can be attributed to the removal of residual lignin and hemicellulose which have been reported to decrease fiber crystallinity (Thygesen et al. 2005).

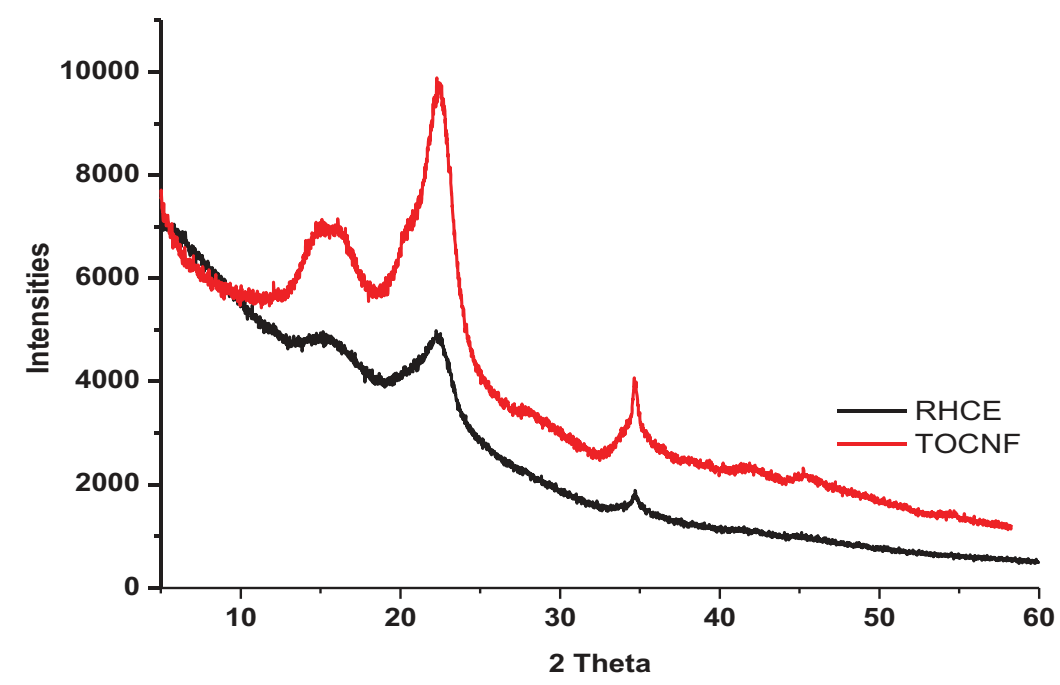

Figure 3. WXRD pattern of Cellulose rice husks (RHCE) and TEMPO-oxidized cellulose nanofibers (TOCNF) isolated from O. sativa husks. 


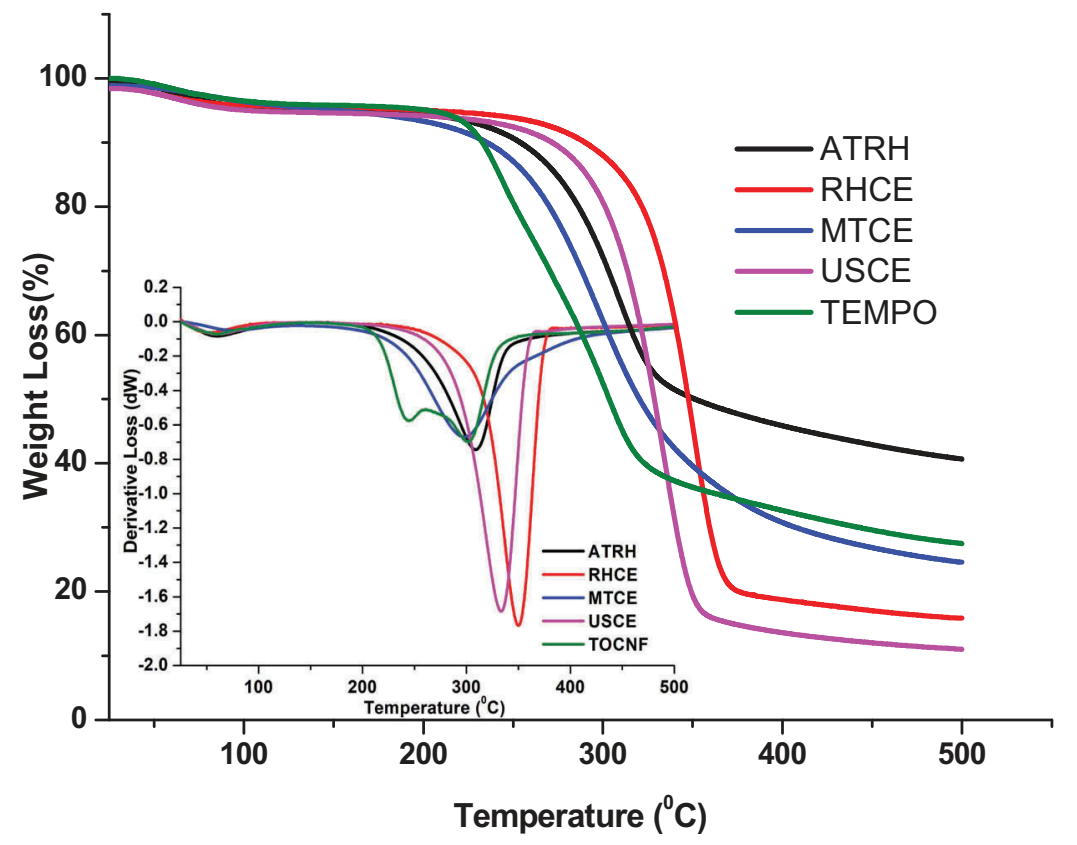

Figure 4. TGA thermogram of ATRH, RHCE, MTCE, USCE and TOCNF. Inset DTGA curves of ATRH, RHCE, MTCE, USCE and TOCNF.

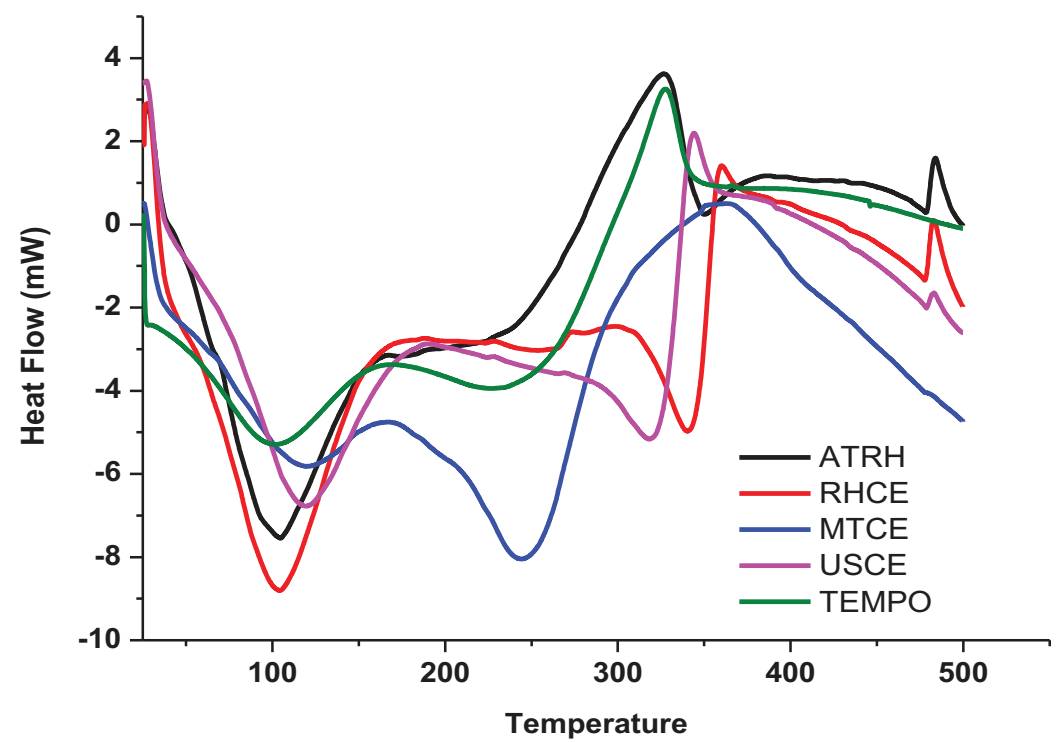

Figure 5. DSC thermogram of ATRH, RHCE, MTCE, USCE and TOCNF.

\section{Thermal analysis}

The TGA and DSC thermogram of rice husk samples subjected to different treatment methods are shown in Figures 4 and 5.

From the DSC thermograms obtained (Figure 5), the samples had very distinct endothermic peaks at the selected working range (Cengiz, Kaya, and Bayramgil 2017). The first endothermic 
change occurs at $70-100^{\circ} \mathrm{C}$ due to evaporation of water and the second endothermic reaction which shows the degradation of hemicellulose structure, which is usually observed between $180^{\circ} \mathrm{C}$ and $300^{\circ}$ C (Poletto 2016). Of all the samples analyzed, only alkali-treated rice husks had a small peak at this region, which is an indication of the presence of residual hemicellulose. The degradation reaction of cellulose starts at $300^{\circ} \mathrm{C}$ and continues to $400^{\circ} \mathrm{C}$ with a maximum mass loss occurring at 351,339 and $305^{\circ} \mathrm{C}$ for alkali-treated rice husks $(\mathrm{ATRH})$, rice husks cellulose (RHCE), mechanically treated (MTCE) and ultrasonicated cellulose (USCE) respectively (Poletto 2016; Poletto, Ornaghi, and Zattera 2014). Generally, cellulose derived from natural fibers has high thermal stabilities due to $\alpha$ cellulose of lignocellulosic structures (Cengiz, Kaya, and Bayramgil 2017). Similar results were observed in TGA thermograms (Figure 4) in which all the samples underwent a small decomposition at around $150^{\circ} \mathrm{C}$ as a result of evaporation of bound water. All samples exhibited the cellulose decomposition process between $290^{\circ} \mathrm{C}$ and $360^{\circ} \mathrm{C}$, which was ascribed to the removal of hemicellulose and lignin during the chemical pretreatment process (Cengiz, Kaya, and Bayramgil 2017). It was also observed that the thermal stability of ATRH, RHCE, MTCE, USCE, TOCNF was in the order TOCNF $<$ MTCE $<$ ATRH $<$ USCE $<$ RHCE with RHCE being the most stable. Lower thermal stability has been reported to be linked to increased crystallinity, fibril and particle sizes as highly crystalline and small particle size materials have a higher heat transfer ability due to increased surface area. Moreover, smaller particle sizes increase the number of end chains which in turn decompose at lower temperatures yielding higher amount of char while the presence of inorganic salts and acids has been known to act as flame retardants during pyrolysis thereby increasing char yield (Nascimento et al. 2016; Yildirim and Shaler 2017).

\section{Hydrodynamic diameters}

The particle size distribution and intensity distribution of TOCNF were determined by dynamic light scattering and the results are depicted in Figure 6.

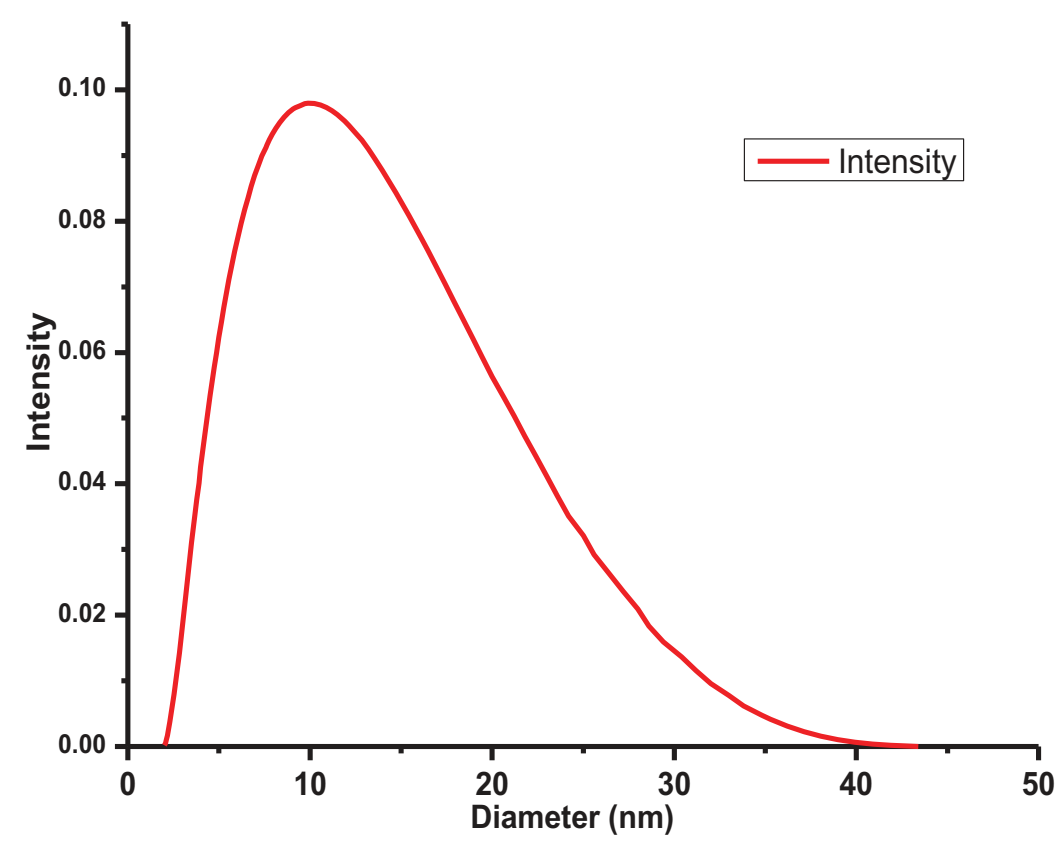

Figure 6. Hydrodynamic diameter of TOCNF obtained by dynamic light scattering for supernatants obtained after centrifugation of TOCNF. 
From dynamic light scattering measurements (Figure 6), it was observed that the diameter of TOCNF was distributed between 2 and $40 \mathrm{~nm}$. Upon oxidation of cellulose, the TOCNF solutions comprise cellulose nanofibers which have greater uniformity, but they tend to aggregate upon drying. As observed in this study, most of the fibers had hydrodynamic diameters between 2 and $5 \mathrm{~nm}$ while some fibers had diameters above this value which can be attributed to the presence of aggregates. The diameter of TOCNF fibers is influenced by the source of cellulose as TOCNF isolated from Acacia pulp, Alfa, sugarcane bagasse, wheat straw, wood and coconut fibers have diameters ranging between 5 and $80 \mathrm{~nm}$. The production of these nanoparticles with diameters below $100 \mathrm{~nm}$ is challenging because of the strong agglomeration tendency which occurs upon drying aqueous cellulose suspensions (Rojas, Bedoya, and Ciro 2015).

\section{SEM and TEM micrographs}

The morphology of rice husk cellulose and TOCNF was examined by SEM and results are depicted in Figure 7.

The chemical treatment of biomass led to the dissolution of lignin and hemicellulose which were subsequently removed yielding cellulose pulp fibers (Figure SF 3). The surface of the native fiber after bleaching was smooth which is an indication that lignin had been removed (Kian et al. 2017; Ruangudomsakul, Ruksakulpiwat, and Ruksakulpiwat 2015). TEMPO-oxidized fibers, on the other hand, had a highly porous surface as compared to native rice husk cellulose (Figure 7), which can be attributed to oxidation of native rice husk cellulose. The TOCNF looked like a continuous irregular mesh of cellulose fibers, occasionally united in the thicker fibers with the average length of the thin fibers being about several hundred nanometers. The large interconnected pores of the cellulose network present in the TOCNF were a result of ice growth during freeze-drying (Yu et al. 2019).

Figure 8-9 shows the fiber length distribution and a TEM micrograph of the unoxidized cellulose fibers with a short, rod-like structure and many aggregates while that of TEMPO-oxidized fibers are depicted in Figure 9. The drying method employed resulted in the formation of fiber aggregates, likely based on strong intermolecular hydrogen bonds between the fibers (Collazo-Bigliardi, OrtegaToro, and Boix 2018; Rojas, Bedoya, and Ciro 2015). Moreover, it has been reported that particle morphology and degree of aggregation are dependent on TEM sample preparation, though some fibers remained isolated which facilitated the determination of fiber length with the help of image processing software (Collazo-Bigliardi, Ortega-Toro, and Boix 2018). The length distribution of

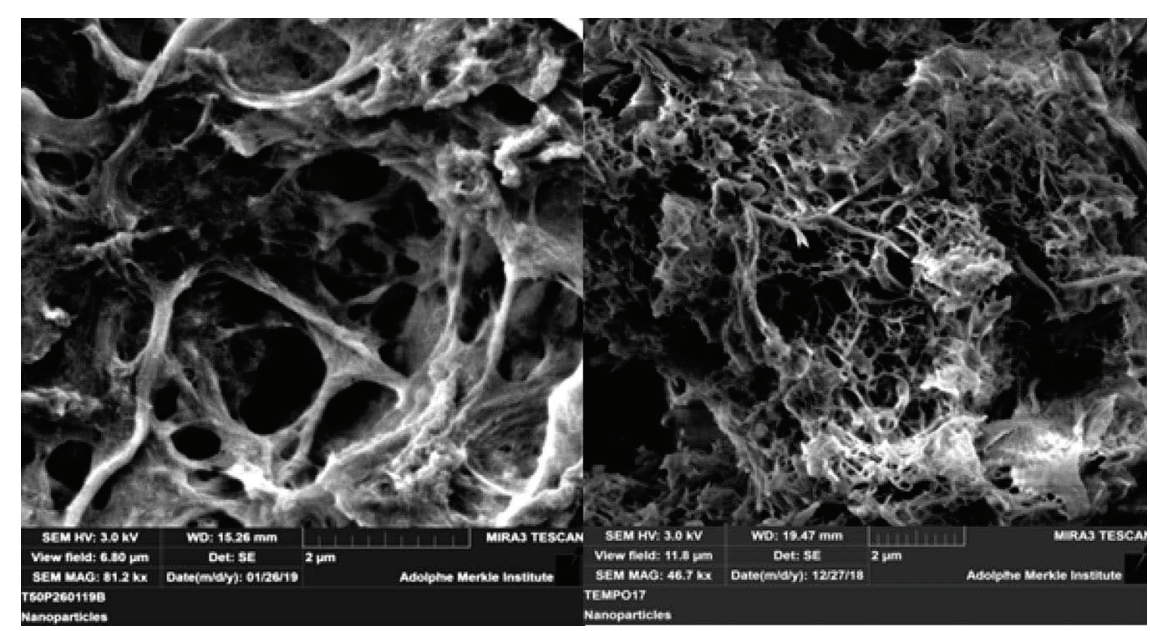

Figure 7. SEM micrographs of TEMPO-oxidized cellulose nanofibers. 


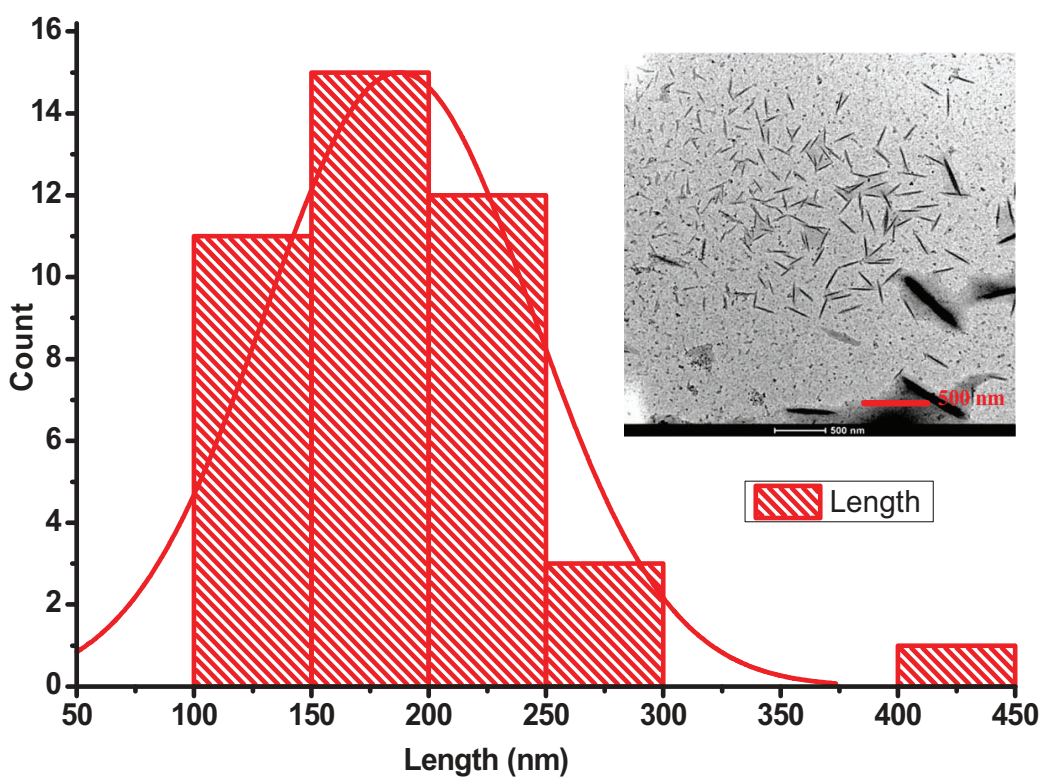

Figure 8. Fiber length distribution of cellulose as determined from TEM micrograph. Inset TEM micrograph of cellulose.

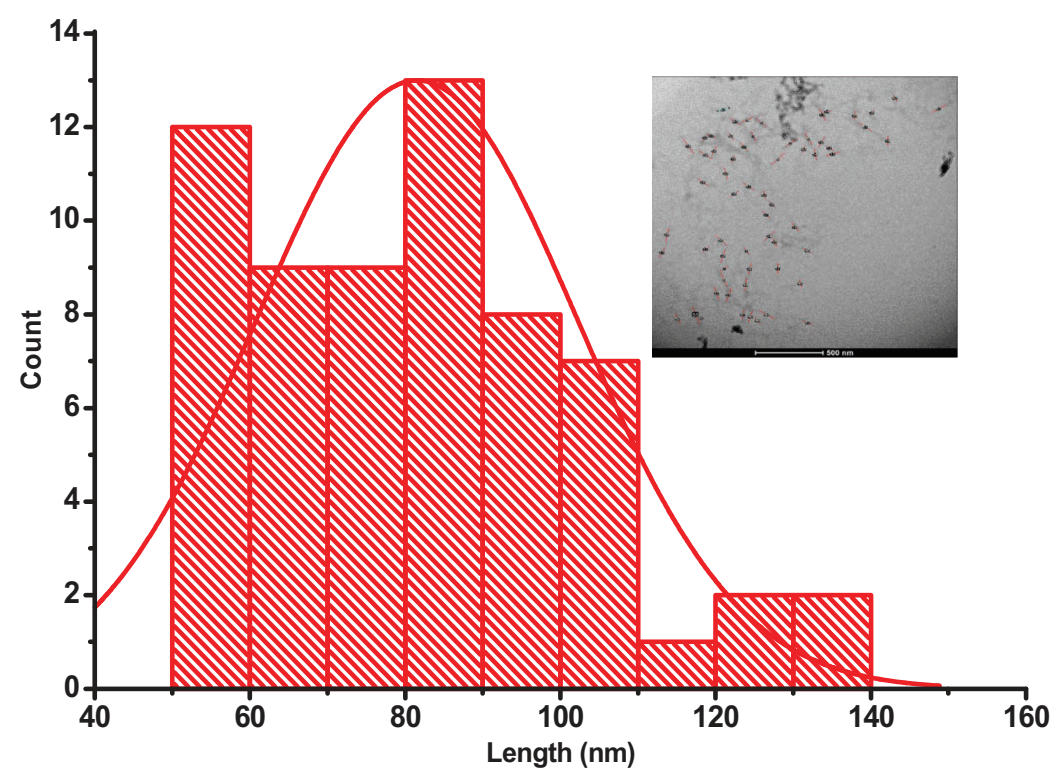

Figure 9. Fiber length distribution of TEMPO-oxidized cellulose. Inset TEM micrograph of TEMPO-oxidized cellulose.

cellulose isolated from rice husks is similar to those that have been reported in the literature when acid hydrolysis was employed to isolate cellulose from different biomass, such as for acid hydrolyzed rice husks cellulose (Collazo-Bigliardi, Ortega-Toro, and Boix 2018), vine shoots (El Achaby et al. 2018), walnut (Hemmati et al. 2018) and roselle fibers (Kian et al. 2017). The nanofiber widths are almost constant, irrespective of cellulose source, whereas the lengths are widely distributed and varied depending on the oxidation and disintegration conditions. 


\section{Conclusions}

Chemical and physical treatment of native cellulose affect fiber properties during its isolation. Both alkali treatment and mechanical grinding of cellulose, ultrasonication at lower ultrasonication power affect both thermal properties and crystallinity of cellulose while TEMPO mediated oxidation changes both morphology, crystallinity and fiber length of cellulose. TEMPO mediated oxidation of cellulose would allow to introduce metal ions and particles in cellulose network which in turn opens the possibility of further functionalization. The fibers isolated in this study were primarily composed of cellulose nanofibers as verified by TEM analysis, though the drying method employed in the study led to aggregation of the fibers. While TEMPO mediated oxidation increases the crystallinity of cellulose and reduces fiber length, it also offers the possibility of utilization of cellulose nanofibers in composite materials. In this way, the use of rice husk as a novel material source makes it possible to obtain new cellulose nanofibers and widens the supply of nanostructured materials.

\section{Acknowledgments}

The authors take this opportunity to acknowledge the financial support of the National research fund, AFRICA-aiJAPAN project JFY 2018/2019, Jomo Kenyatta University of Agriculture, and Technology for their financial support. Lastly, the authors are thankful to the Federal commission of scholarships (FCS) Switzerland for a one-year research exchange program at the Chemistry department, University of Fribourg.

\section{Funding}

This work was supported by the National Commission for Science, Technology and Innovation [2016/2017]; Africa-aiJapan [JFY 2018/2019].

\section{ORCID}

Edwin S. Madivoli (D) http://orcid.org/0000-0003-3992-5097

Patrick G. Kareru (D) http://orcid.org/0000-0001-9622-6554

Anthony N. Gachanja (D) http://orcid.org/0000-0001-6166-6744

Samuel M. Mugo (D) http://orcid.org/0000-0002-0015-1947

Katharina M. Fromm (D) http://orcid.org/0000-0002-1168-0123

\section{References}

Barbash, V. A., O. V. Yaschenko, and O. M. Shniruk. 2017. Preparation and properties of nanocellulose from organosolv straw pulp. Nanoscale Research Letters 12 (1):241. doi:10.1186/s11671-017-2001-4.

Barbosa, L. C., C. R. Maltha, A. J. Demuner, C. M. Cazal, E. L. Reis, and J. L. Colodette. 2013. A rapid method for quantification of carboxyl groups in cellulose pulp. Bioresources 1 (8):1043-54.

Begun, P. S., R. Joseph, D. Joseph, P. Kumar, and E. P. Ayswarya. 2013. Synthesis, characterization and application of Rice husks nanosilica in natural rubber. International Journal of Science, Environment and Technology 2 (5):1027-35.

Bhimte, N. A., and P. T. Tayade. 2007. Evaluation of microcrystalline cellulose prepared from sisal fibers as a tablet excipient: A technical note. AAPS PharmSciTech 8 (1):E56- E62. doi:10.1208/pt0801008.

Bian, H., Y. Gao, J. Luo, L. Jiao, W. Wu, G. Fang, and H. Dai. 2019a. Lignocellulosic nanofibrils produced using wheat straw and their pulping solid residue: From agricultural waste to cellulose nanomaterials. Waste Management 91:1-8. doi:10.1016/j.wasman.2019.04.052.

Bian, H., J. Luo, R. Wang, X. Zhou, S. Ni, R. Shi, G. Fang, and H. Dai. 2019b. Recyclable and reusable maleic acid for efficient production of cellulose nanofibrils with stable performance. ACS Sustainable Chemistry \& Engineering 7 (24):20022-31. doi:10.1021/acssuschemeng.9b05766.

Boufi, S., and A. Chaker. 2016. Easy production of cellulose nanofibrils from corn stalk by a conventional high speed blender. Industrial Crops and Products 93:39-47. doi:10.1016/j.indcrop.2016.05.030.

Camacho, D. H., S. R. Gerongay, and J. P. Macalinao. 2013. Cladophora cellulose-polyaniline composite for remediation of toxic chromium (VI). Cellulose Chemistry and Technology 47:125-32. 
Cengiz, A., M. Kaya, and N. P. Bayramgil. 2017. Flexural stress enhancement of concrete by incorporation of algal cellulose nanofibers. Construction and Building Materials 149:289-95. doi:10.1016/j.conbuildmat.2017.05.104.

Chen, Y., Q. Wu, B. Huang, M. Huang, and X. Ai. 2014. Isolation and characteristics of cellulose and nanocellulose from lotus leaf stalk agro-wastes. Bioresources 10 (1):684-96. doi:10.15376/biores.10.1.684-696.

Ciolacu, D., F. Ciolacu, and V. I. Popa. 2011. Amorphous cellulose-structure and characterization. Cellulose Chemistry and Technology 45 (1):13.

Collazo-Bigliardi, S., R. Ortega-Toro, and A. C. Boix. 2018. Isolation and characterisation of microcrystalline cellulose and cellulose nanocrystals from coffee husk and comparative study with rice husk. Carbohydrate Polymers 191:205-15. doi:10.1016/j.carbpol.2018.03.022.

Corgie, S. C., H. M. Smith, and L. P. Walker. 2011. Enzymatic transformations of cellulose assessed by quantitative high-throughput fourier transform infrared spectroscopy (QHT-FTIR). Biotechnology and Bioengineering 108 (7):1509-20. doi:10.1002/bit.23098.

de Aguiar, J., T. J. Bondancia, P. C. Claro, L. C. Mattoso, C. S. Farinas, and J. M. Marconcini. 2020. Enzymatic deconstruction of sugarcane bagasse and straw to obtain cellulose nanomaterials. ACS Sustainable Chemistry \& Engineering 8 (5):2287-99. doi:10.1021/acssuschemeng.9b06806.

El Achaby, M., N. El Miri, H. Hannache, S. Gmouh, H. Ben Youcef, and A. Aboulkas. 2018. Production of cellulose nanocrystals from vine shoots and their use for the development of nanocomposite materials. International Journal of Biological Macromolecules 117 (2018):592-600. doi:10.1016/j.ijbiomac.2018.05.201.

Hassan, E. A., and M. L. Hassan. 2016. Rice straw nanofibrillated cellulose films with antimicrobial properties via supramolecular route. Industrial Crops and Products 93:142-51. doi:10.1016/j.indcrop.2016.02.025.

Hemmati, F., S. M. Jafari, M. Kashaninejad, and M. B. Motlagh. 2018. Synthesis and characterization of cellulose nanocrystals derived from walnut shell agricultural residues. International Journal of Biological Macromolecules 120:1216-24. doi:10.1016/j.ijbiomac.2018.09.012.

Hooshmand, S., Y. Aitomaki, L. Berglund, A. P. Mathew, and K. Oksman. 2017. Enhanced alignment and mechanical properties through the use of hydroxyethyl cellulose in solvent-free native cellulose spun filaments. Composites Science and Technology 150 (2017):79-86. doi:10.1016/j.compscitech.2017.07.011.

Islam, M. S., N. Kao, S. Bhattacharya, R. Gupta, and H. J. Choi. 2018. Potential aspect of rice husk biomass in Australia for nanocrystalline cellulose production. Chinese Journal of Chemical Engineering 26 (3):465-76. doi:10.1016/j. cjche.2017.07.004

Isogai, A. 2018. Development of completely dispersed cellulose nanofibers. Proceedings of the Japan Academy, Series B 94 (4):161-79. doi:10.2183/pjab.94.012.

Johar, N., I. Ahmad, and A. Dufresne. 2012. Extraction, preparation and characterization of cellulose fibres and nanocrystals from rice husk. Industrial Crops and Products 37 (1):93-99. doi:10.1016/j.indcrop.2011.12.016.

Jonoobi, M., J. Harun, A. P. Mathew, M. Z. B. Hussein, and K. Oksman. 2010. Preparation of cellulose nanofibers with hydrophobic surface characteristics. Cellulose 17 (2):299-307. doi:10.1007/s10570-009-9387-9.

Jorfi, M., and J. Foster. 2015. Recent advances in nanocellulose for biomedical applications. Journal of Applied Polymer Science 132 (14):1-19. doi:10.1002/app.41719.

Kar, K. K., Rana, S., \& Pandey, J. (2015). Handbook of polymer nanocomposites processing, performance and application. Berlin/Heidelberg, Germany: Springer.

Karimi, K., and M. J. Taherzadeh. 2016. A critical review of analytical methods in pretreatment of lignocelluloses: Composition, imaging, and crystallinity. Bioresource Technology 200:1008-18. doi:10.1016/j.biortech.2015.11.022.

Kian, L. K., M. Jawaid, H. Ariffin, and O. Y. Alothman. 2017. Isolation and characterization of microcrystalline cellulose from roselle fibers. International Journal of Biological Macromolecules 103:931-40. doi:10.1016/j. ijbiomac.2017.05.135

Madivoli, E. S., P. G. Kareru, A. N. Gachanja, S. M. Mugo, M. K. Murigi, P. K. Kairigo, C. Kipyegon, J. Mutembei, and F. Njonge. 2016. Adsorption of selected heavy metals on modified nano cellulose. International Research Journal of Pure and Applied Chemistry 12 (3):1-9. doi:10.9734/IRJPAC/2016/28548.

Menon, M. P., R. Selvakumar, P. Suresh Kumar, and S. Ramakrishna. 2017. Extraction and modification of cellulose nanofibers derived from biomass for environmental application. RSC Advances 7 (68):42750-73. doi:10.1039/ C7RA06713E.

Murigi, M., E. Madivoli, M. M. Mathenyu, P. Kareru, A. Gachanja, P. N. Githira, ... M. Githua. 2014. Comparison of physicochemical characteristics of microcrystalline cellulose from four abundant Kenyan biomasses. Internation Journal of Scientific Research 1 (2):53-63.

Nascimento, P., R. Marim, G. Carvalho, and S. Mali. 2016. Nanocellulose produced from rice hulls and its effect on the properties of biodegradable starch films. Materials Research 19 (1):167-74. doi:10.1590/1980-5373-MR-2015-0423.

Okita, Y., S. Fujisawa, T. Saito, and A. Isogai. 2010. TEMPO-oxidized cellulose nanofibrils dispersed in organic solvents. Biomacromolecules 12 (2):518-22. doi:10.1021/bm101255x.

Peng, Y., Y. Han, and D. J. Gardner. 2012. Spray-drying cellulose nanofibrils: Effect of drying process parameters on particle morphology and size distribution. Wood and Fibre Science 44 (4):448-61.

Poletto, M. 2016. Thermal degradation and morphological aspects of four wood species used in lumber industry. Revista Árvore 40 (5):941-48. doi:10.1590/0100-67622016000500018. 
Poletto, M., H. L. Ornaghi, and A. J. Zattera. 2014. Native cellulose: Structure, characterization and thermal properties. Materials 7 (9):6105-19. doi:10.3390/ma7096105.

Ponce, C., J. Chanona, V. Garibay, E. Palacios, G. Calderon, and R. Sabo. 2013. Functionalization of agave cellulose nanoparticles and its characterization by microscopy and spectroscopy techniques. Microscopy and Microanalysis 19 (S2):200-01. doi:10.1017/S1431927613002997.

Rohaizu, R., and W. D. Wanrosli. 2017. Sono-assisted TEMPO oxidation of oil palm lignocellulosic biomass for isolation of nanocrystalline cellulose. Ultrasonics Sonochemistry 34:631-39. doi:10.1016/j.ultsonch.2016.06.040.

Rojas, J., M. Bedoya, and Y. Ciro. 2015. Current trends in the production of cellulose nanoparticles and nanocomposites for biomedical applications. In Cellulose-fundamental aspects and current trends, Editor: Matheus Poletto, 193-228. Vigo, Spain: Intech.

Ruangudomsakul, W., C. Ruksakulpiwat, and Y. Ruksakulpiwat. 2015. Preparation and characterization of cellulose nanofibers from cassava pulp. In Macromolecular Symposia 354 (1):170-76. doi:10.1002/masy.201400096.

Szczęsna-Antczak, M., J. Kazimierczak, and T. Antczak. 2012. Nanotechnology-methods of manufacturing cellulose nanofibres. Fibres \& Textiles in Eastern Europe 2 (91):8-12.

Thygesen, A., J. Oddershede, H. Lilholt, A. B. Thomsen, and K. Stahl. 2005. On the determination of crystallinity and cellulose content in plant fibres. Cellulose 12 (6):563-76. doi:10.1007/s10570-005-9001-8.

Torres, F. G., O. P. Troncoso, C. Torres, and C. J. Grande. 2013. Natural composites and nanocomposites. In Advances in natural polymers, composites and nanocomposites, ed. T. Sabu, P. M. Visakh, and A. Mathew, 21-54. Berlin: Springer.

Wang, L., D. J. Gardner, and D. W. Bousfield. 2017. Cellulose nanofibril-reinforced polypropylene composites for material extrusion: Rheological properties. Polymer Engineering and Science 1-8. doi:10.1002/pen.24615.

Yildirim, N., and S. Shaler. 2017. A study on thermal and nanomechanical performance of cellulose nanomaterials (CNs). Materials 10 (7):1-12. doi:10.3390/ma10070718.

Yu, W., C. Wang, Y. Yi, W. Zhou, H. Wang, Y. Yang, and Z. Tan. 2019. Choline chloride-based deep eutectic solvent systems as a pretreatment for nanofibrillation of ramie fibers. Cellulose 26 (5):3069-82. doi:10.1007/s10570-01902290-7.

Zhang, X. Z., and Y. H. Zhang. 2013. Cellulases: Characteristics, sources, production, and applications. In Bioprocessing technologies in biorefinery for sustainable production of fuels, chemicals, and polymers, ed. S. T. Yang, H. El-Ensashy, and T. Nutta, 131-46. New Jersey: John Wiley \& Sons.

Zhou, Y., T. Saito, L. Bergstrom, and A. Isogai. 2018. Acid-free preparation of cellulose nanocrystals by TEMPO oxidation and subsequent cavitation. Biomacromolecules 19 (2):633-39. doi:10.1021/acs.biomac.7b01730.

Zimmermann, M. V., C. Borsoi, A. Lavoratti, M. Zanini, A. J. Zattera, and R. M. Santana. 2016. Drying techniques applied to cellulose nanofibers. Journal of Reinforced Plastics and Composites 35 (8):1-10. doi:10.1177/ 0731684415626286 . 